\title{
MODELO COMPUTACIONAL PARA A SELEÇÃO DE PORTFÓLIO DE AÇÕES UTILIZANDO A TEORIA DE MARKOWITZ
}

Geraldo Motta Azevedo Junior Doutor em Engenharia Elétrica pela Universidade Federal do Rio de Janeiro, RJ, Brasil geraldomajr@gmail.com

Carlos Manoel Falcão Nunes Especialista em Gestão Econômica pela Universidade Estadual do Rio de Janeiro, RJ, Brasil cfalcaonunes@gmail.com

\section{RESUMO}

O presente artigo aborda o desenvolvimento de um modelo computacional, para apoio a tomada de decisão, na seleção de ações mais rentáveis e com menor risco ao investidor. Para a construção do modelo é utilizada a linguagem de programação e o ambiente de desenvolvimento $\mathrm{R}$, além da plataforma de publicação shinyapp.io; tendo como base de cálculo para o modelo matemático a Teoria de Markowitz. A seleção do período desejado para a análise dos preços das ações, a seleção das ações, a demonstração e a apresentação dos resultados dos cálculos realizados são disponibilizados através de uma API (Application Programming Interface).

Palavras Chave: Teoria de Markowitz, Fronteira Eficiente, Risco e Retorno.

\section{COMPUTATIONAL MODEL FOR THE SELECTION OF ASSET PORTFOLIO USING MARKOWITZ THEORY}

\begin{abstract}
This article discusses the development of a computational model, to support decision making, in the selection of more profitable actions and with less risk to the investor. For construction of the model will be used the programming language and development environment $\mathrm{R}$, in addition to the publication platform shinyapp.io; based on the Markowitz Theory Model. Selection of the desired period for asset price analysis, asset selection, demonstration and presentation of the results of the calculations are made available through an API (Application Programming Interface).
\end{abstract}

Keywords: Markowitz Theory, Efficient Frontier, Risk and Return.

\section{INTRODUÇÃO}


O objetivo principal do presente trabalho é a elaboração de um modelo computacional para seleção de carteira de investimento mais atraente a partir de métodos quantitativos financeiros apoiados na teoria de Markowitz.

Com este estudo pretende-se conseguir entender, quantitativamente o cenário de evolução e comportamento dos preços das ações estudadas ao longo do tempo, com a finalidade de apoiar a decisão do investidor na seleção de ações que possuam investimentos mais atrativos considerando a postura do investidor em relação ao risco, por ser esta uma questão de natureza pessoal.

O investimento em ações envolve assumir certo risco com relação às oscilações de suas cotações no mercado. Um dos principais aspectos que permeiam o mercado de ações, em especial a questão da escolha das ações e suas quantidades, é a relação risco / retorno e investidor. Desta forma, é preciso que existam meios racionais para a tomada de decisão que possam ser usados por investidores de diversos perfis sejam eles propensos a riscos, indiferentes ao risco ou mesmo avessos ao risco.

\subsection{Investimento}

As necessidades humanas são diversas e vão desde as necessidades vitais e biológicas, até outras necessidades não vitais, que são igualmente valorizadas e baseadas em critérios de satisfação individual. A satisfação destas necessidades se dá, principalmente pelo consumo de recursos naturais e em boa parte destas necessidades, a satisfação está diretamente ligada a desembolso de capital.

Ao longo da vida, as pessoas ganham e gastam dinheiro, com o objetivo principal de satisfazer suas necessidades. Este fluxo de capital proporcionado pela incansável busca de suas satisfações nem sempre resulta num valor líquido nulo, ou seja, na maioria dos casos existe um déficit ou um superávit no resultado final dos recebimentos e gastos.

No caso de um resultado negativo, as pessoas são levadas a recorrer a empréstimos e outras formas de crédito para honrar com suas obrigações.

Já no caso de um resultado positivo com relação a seus recebimentos e obrigações, as pessoas possuem diversas alternativas quanto ao destino do capital excedido. Uma alternativa é satisfazer desejos até então privados pela não posse de capital necessário para sua realização imediata. Outra alternativa é a privação de seus desejos atuais e a aceitação de se desfazer da posse imediata do capital excedido visando no futuro um recebimento maior que o capital atual. Esta escolha entre a posse imediata do capital e a 
esperança de um recebimento que justifique esta privação é chamada de investimento. (REILLY E BROWN, 1997).

\subsection{Bolsa de valores, mercadoria e futuros}

A bolsa de valores de São Paulo, BOVESPA, fornecia toda a estrutura para negociação de títulos e valores mobiliários até o ano de 2008 sob a forma de sociedade civil sem fins lucrativos. Desse ano em diante a Bolsa transformou-se em uma empresa sob o caráter de sociedade anônima e foi realizado o lançamento de suas ações para negociação sob o nome de Bovespa Holding.

Logo em seguida, um processo bastante similar ocorreu com a Bolsa de Mercadorias e Futuros, BM\&F, local de negociação de contratos futuros e outros ativos, também com abertura de capital e ações negociadas junto ao público investidor.

Da fusão destas duas empresas, agora sob o regime de sociedade anônima, nasceu a Bolsa de Valores, Mercadoria e Futuros, a BM\&FBOVESPA, onde são negociados além das ações, os contratos de derivativos em uma plataforma única. Os investidores podem adquirir ações de companhias, bem como contratos futuros de dólar, ouro e commodities.

\subsection{Ações}

A própria origem das sociedades anônimas sugere que a origem do mercado de ações se deu quando o mercado de crédito deixou de ser eficiente para garantir o fluxo de recursos nas condições adequadas, especialmente em termos de prazo e custo, para a atividade produtiva.

Segundo Miranda Valverde apud Oliveira (1983), a primeira S.A. data de 1407, quando a República de Gênova, não podendo pagar títulos de dívida por ela emitidos, transformou-se em ações nominativas, inscritas nos registros e livremente alienáveis e cotadas no mercado.

Segundo Pinheiro (2001, p.114), ações ordinárias têm como característica principal o direito ao voto. Numa sociedade anônima é por meio do voto que o acionista 
tem direito legal de controle da organização.

Segundo Pinheiro (2001, p.112), ações preferenciais têm como característica fundamental a prioridade sobre as ações ordinárias no recebimento de dividendos e de receber, no caso de dissolução da sociedade, a sua parte.

Nos próximos itens serão apresentadas uma revisão dos fundamentos teóricos para a análise e seleção de ações, a descrição da situação atual, a descrição dos procedimentos computacionais para a resolução do problema proposto no artigo e finalmente o resultado computacional e a revisão bibliográfica.

\section{DESENVOLVIMENTO}

Aqui será apresentada a revisão da literatura que permite embasar o desenvolvimento dos cálculos necessários para utilização da Teoria de Markowitz. Além disso, serão definidas todas as tecnologias que suportam a modelagem e a execução dos algoritmos para a resolução do problema de composição de portfólio de investimento.

\subsection{Revisão de literatura}

O tipo de problema de portfólio a ser estudado nesse artigo caracteriza-se pela escolha de como investir o capital disponível entre as várias ações existentes no mercado. A estratégia pertinente a resolução desse tipo de problema envolve tanto a maximização do retorno do investimento, como a minimização do risco de perda de capital em virtude das flutuações dos preços do mercado. Naturalmente, estes objetivos são contraditórios e cabe ao investidor decidir como combiná-los.

A teoria de Markowitz mostra que na medida em que o investidor diversifica sua carteira, escolhendo ativos com correlação negativa, ele consegue reduzir, ou até mesmo eliminar do ponto de vista teórico o risco diversificável, que é não sistemático.

Segundo Assaf Neto (2011, p.252), no estudo da diversificação, o risco de um ativo é avaliado pela contribuição ao risco total da carteira. Elevando-se de maneira diversificada, o número de títulos em uma carteira, é possível promover a redução do risco, porém a uma taxa decrescente. A partir de um determinado número de títulos, a redução do risco praticamente deixa de existir, conservando a carteira, de forma sistemática certo nível de risco. Assim, até mesmo carteiras bem diversificadas costumam manter certo grau de risco, impossível de ser eliminado pela diversificação, denominado 
risco sistemático.

A razão pela qual a diversificação melhora a relação risco e retorno é que, na medida em que novos ativos são adicionados a uma carteira de investimentos, o risco total, medido pelo desvio-padrão da carteira, é reduzido; já o retorno da carteira é determinado pela média ponderada dos retornos dos ativos individuais. Em resumo pode-se dizer que quanto menor a correlação dos retornos, maior a redução do risco pela diversificação.

A expressão geral de cálculo do risco, fornecida pelo desvio padrão, de uma carteira contendo $\mathrm{n}$ ativos, baseando-se no modelo de portfólio desenvolvido por Markowitz é a seguinte:

$$
\sigma_{p}=\sqrt[2]{\sum_{i=1}^{n} \sum_{i=1}^{n} W_{i} W_{j} \operatorname{CORR}_{I, J} \sigma_{I} \sigma_{J}}
$$

Onde:

$\sigma_{p} \sigma_{p}=$ risco do portfólio.

$\sigma_{i} \sigma_{i}=$ risco do ativo $\mathrm{i}$.

$\sigma_{j} \sigma_{j}=$ risco do ativo $\mathbf{j}$.

$W_{i} W_{j} W_{i} W_{j}=$ respectivamente a participação do ativo i e do ativo j.

$\operatorname{CORR}_{i, j} \operatorname{CORR_{i,j}}=$ correlação entre o ativo i e o ativo j.

Por exemplo, o desvio-padrão de uma carteira composta de três ativos $(A, B, C)$ é apurado a partir da identidade geral anunciada, da seguinte maneira:

$$
\sigma_{p}=\left[\begin{array}{c}
\left(W_{A}^{2} \cdot \sigma_{A}^{2}\right)+\left(W_{B}^{2} \cdot \sigma_{B}^{2}\right)+\left(W_{C}^{2} \cdot \sigma_{C}^{2}\right)+\left(2 \cdot W_{A} \cdot W_{B} \operatorname{COV}_{A, B}\right)+ \\
\left(2 \cdot W_{A} \cdot W_{C} \cdot \operatorname{COV}_{A, C}\right)+\left(2 \cdot W_{B} \cdot W_{C} \cdot \operatorname{COV}_{B, C}\right)
\end{array}\right] 1 / 2
$$

Onde:

$\sigma_{p} \sigma_{p}=$ risco do portfólio.

$\sigma_{A} \sigma_{B} \sigma_{C} \sigma_{A} \sigma_{B} \sigma_{C}=$ respectivamente risco ativo $\mathrm{A}$, risco ativo $\mathrm{B}$ e risco do ativo $\mathrm{C}$.

$W_{A} W_{B} W_{C} W_{A} W_{B} W_{C}=$ respectivamente a participação do ativo $\mathrm{A}$, do ativo $\mathrm{B}$ e do 
ativo $\mathrm{C}$.

$\operatorname{COV}_{A, B} \operatorname{COV}_{A, B}=$ covariância entre A e B.

$\operatorname{COV}_{A, C} \operatorname{COV}_{A, C}=$ covariância entre A e $\mathrm{C}$.

$C O V_{B, C} C O V_{B, C}=$ covariância entre B e C.

Dessa forma, ao compor uma carteira de ativos, também chamada Portfólio, sua medida relevante passa a ser o risco sistemático, já que o outro componente pode ser eliminado pela diversificação. Isso pode ser visto no Gráfico 1.

Gráfico 1 - Redução do risco pela diversificação

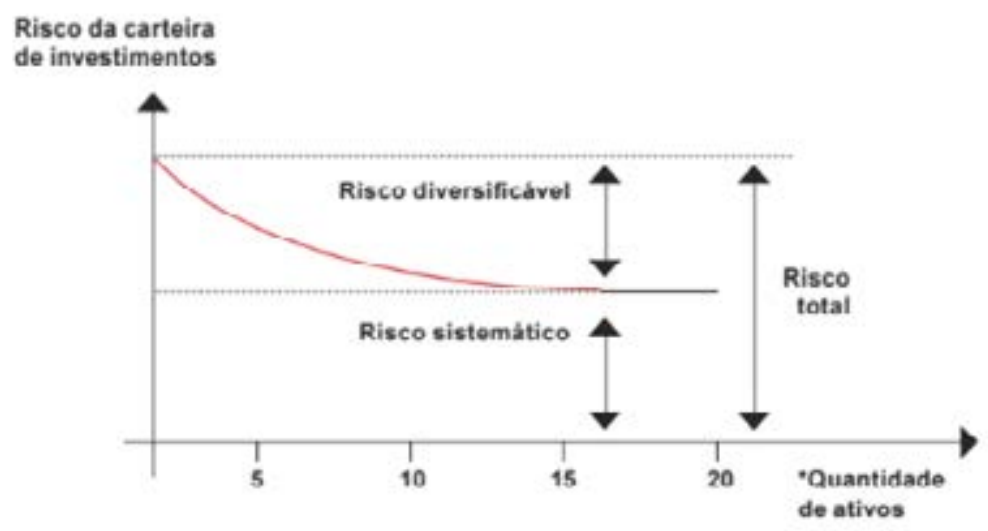

Fonte: (ASSAF NETO, 2011).

Em outras palavras, na fronteira eficiente de Markowitz, é possível selecionar uma carteira que apresenta, para um determinado retorno o menor risco possível, conforme é mostrado no Gráfico 2. 


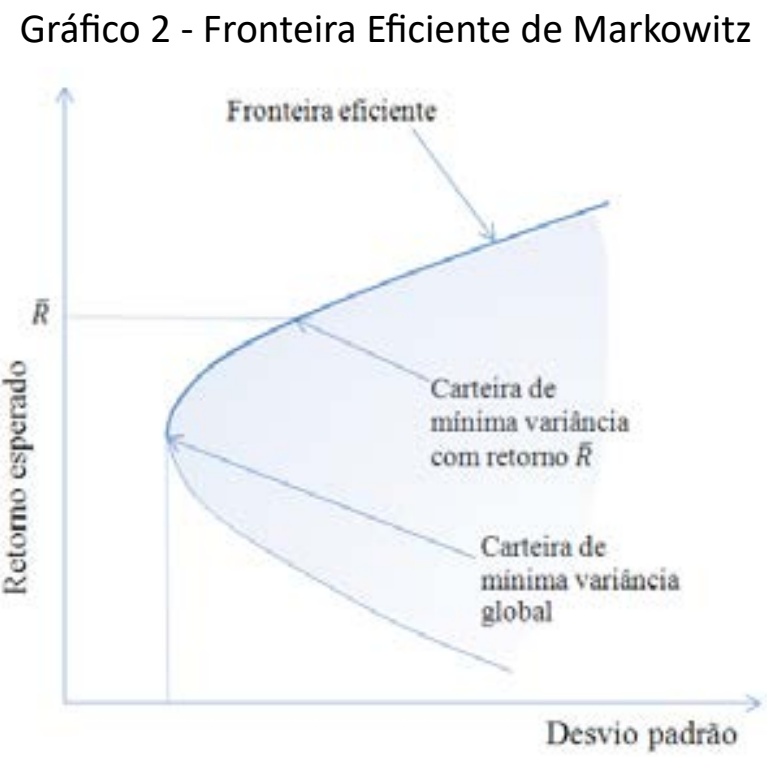

Fonte: (ASSAF NETO, 2011).

\subsection{Situação atual}

Todos os dias as pessoas ganham e gastam dinheiro, com o objetivo principal de satisfazer suas necessidades pessoais, tanto físicas quanto psicológicas. Durante este processo de ganho e gasto de dinheiro pode ocorrer um saldo positivo destas diferenças, ou seja, o ganho ser maior do que o gasto. Quando isso acontece, tem início o dilema do investidor sobre qual a melhor destinação para os valores excedentes.

Decisões financeiras em geral não são tomadas em ambiente de total incerteza em relação aos seus resultados, isto porque, as variáveis econômicas que definem os recursos dos preços e retornos dos ativos negociados no mercado que são identificadas no câmbio, na taxa básica de juros da economia, na inflação, entre outros podem ser avaliadas pelo investidor, porém estão fora do seu controle.

Uma questão fundamental para que a operação com ações seja um investimento vantajoso é o momento oportuno de entrar e sair do mercado. A identificação do momento oportuno exige um acompanhamento e análises frequentes de cenários econômicos, mercado financeiro e desempenho das empresas que compõe o portfólio. Outra questão fundamental é a busca da minimização constante do risco diversificável. 
Ou seja, o diferencial de um bom investidor está em saber se antecipar aos movimentos do mercado e saber reduzir os riscos dos seus investimentos através de uma boa diversificação de ações.

Esta não é uma tarefa fácil a começar pela quantidade de ações disponíveis. Segundo (www.bmfbovespa.com.br) existem mais de 350 empresas listadas negociando ações em diversos setores como: bens industriais, consumo cíclico, consumo não cíclico, financeiro e outros, materiais básicos, petróleo, gás e biocombustíveis, saúde, tecnologia da informação e utilidade pública. Dentre as inúmeras carteiras que podem ser formadas com os ativos disponíveis, o processo de seleção de carteira deve ser capaz de apontar aquela que irá maximizar o grau de satisfação do investidor.

Em resumo, a ideia deste artigo é construir e disponibilizar uma ferramenta que seja capaz de auxiliar uma tomada de decisão em relação à escolha do peso e das ações que podem compor a carteira de um investidor. Deve-se ressaltar que esta ferramenta utiliza como insumo apenas os preços praticados ao longo do tempo e não leva em consideração qualquer outra variável do cenário econômico, político ou social. Sendo assim, a mesma não tem a pretensão de ser uma ferramenta definitiva para a seleção do portfólio de uma carteira, mas uma ferramenta baseada na Teoria de Markowitz, que pode ser utilizada na tomada de decisão de um investidor qualquer.

\subsection{Estudo de caso}

Neste item, serão definidas todas as tecnologias que permitem dar suporte à modelagem e à execução dos algoritmos para a resolução do problema de composição de portfólio de investimento considerando quatro ações que serão definidas pelo investidor. No primeiro momento de execução, serão coletadas as séries históricas de preços das empresas escolhidas aleatoriamente dentro da lista que será disponibilizada na aplicação. Em seguida o dado será coletado do site (https://finance.yahoo.com/) que disponibiliza informações de diversas bolsas inclusive da BM\&FBOVESPA. Também serão apresentados os resultados das primeiras linhas e das colunas de forma a auxiliar o entendimento sobre a base, possibilitando a modelagem correta das variáveis, para os modelos.

Como tecnologia para apoiar a construção da aplicação será utilizado o RStudio (IDE para o R), o gerenciamento de pacotes e todas as bibliotecas $\mathrm{R}$ ? específicas para otimização de portfólio, matemática e plotagem de gráficos ? utilizadas; além disso, serão 
conceituadas as técnicas necessárias para garantir a execução correta dos algoritmos, como o pré-processamento de dados, geração da fronteira eficiente e apresentação dos resultados da composição de portfólio de menor risco e da composição de portfólio de maior retorno.

\subsubsection{Bibliotecas do RStudio}

O RStudio já possui algumas bibliotecas e bancos pré-instalados no ambiente. Entretanto, pode ser necessário instalar novas bibliotecas, dependendo da atividade que deseja ser realizada. Para a execução da solução proposta neste artigo será necessário a instalação de algumas bibliotecas que não estão pré-instaladas no RStudio.

Seguem as bibliotecas necessárias e uma breve descrição das mesmas.

\subsubsection{Biblioteca - quantmod}

Segundo (https://cran.r-project.org/web/packages/quantmod/), a biblioteca quantmod para $\mathrm{R}$ é projetada para auxiliar o profissional que realiza modelagem quantitativa financeira no desenvolvimento, teste e implantação de modelos comerciais baseados em estatística.

\subsubsection{Biblioteca - fPortfolio}

Segundo (https://cran.r-project.org/web/packages/fPortfolio/), a biblioteca fPortfolio é uma coleção muito poderosa de funções para otimizar portfólios e analisálos de diferentes pontos de vista. Foi publicada em 2017, e teve como base o projeto Rmetrics motivado em promover inovações em finanças e informática, combinando análise exploratória de dados, modelagem estatística e prototipagem de modelos.

\subsubsection{Biblioteca - timeSeries}

Segundo (https://cran.r-project.org/web/packages/timeSeries/), a biblioteca 
timeSeries possui várias funções para o trato de séries temporais. Foi publicada em 2017 e, também teve como base, o projeto Rmetrics, assim como, a biblioteca fPortfolio.

\subsubsection{Biblioteca - ggplot2}

Segundo (https://cran.r-project.org/web/packages/ggplot2/), a biblioteca ggplot2 tem por finalidade criar visualizações de dados elegantes usando a gramática de gráficos.

\subsubsection{Biblioteca - plotly}

Segundo (https://cran.r-project.org/web/packages/plotly/) a biblioteca plotly é capaz de converter facilmente os gráficos pela biblioteca 'ggplot2' para uma versão interativa baseada na Web e / ou criar visualizações baseadas na web diretamente do R.

\subsubsection{Biblioteca - flexdashboard}

Segundo (https://cran.r-project.org/web/packages/flexdashboard/), a biblioteca flexdashboard converte um documento $\mathrm{R}$ em uma grade orientada com painel de controle. O painel adapta com flexibilidade o tamanho de seus componentes ao conteúdo de páginas web, assim como, dispositivos móveis como celulares e tablets.

\subsubsection{Etapas de Execução no RStudio}

Conforme informado no início deste capítulo a primeira etapa consiste em carregar as bases de dados das ações desejadas, listadas no BM\&FBOVESPA e, que se encontram disponíveis no site (https://finance.yahoo.com/).

As bases disponíveis possuem sete colunas: data da operação na bolsa, preço de abertura do dia, preço máximo do dia, preço mínimo do dia, preço de fechamento do dia, volume de ações negociadas do dia e preço ajustado. Contudo para a realização deste 
trabalho serão utilizadas apenas a data da operação na bolsa e o preço de fechamento do dia.

Como primeiro passo após a abertura do RStudio é selecionado o diretório de trabalho e, posteriormente, são ativadas as bibliotecas necessárias para a execução do trabalho proposto. Na Figura 1 é mostrado o código em R:

Figura 1- Código de instalação das bibliotecas $\mathrm{R}$

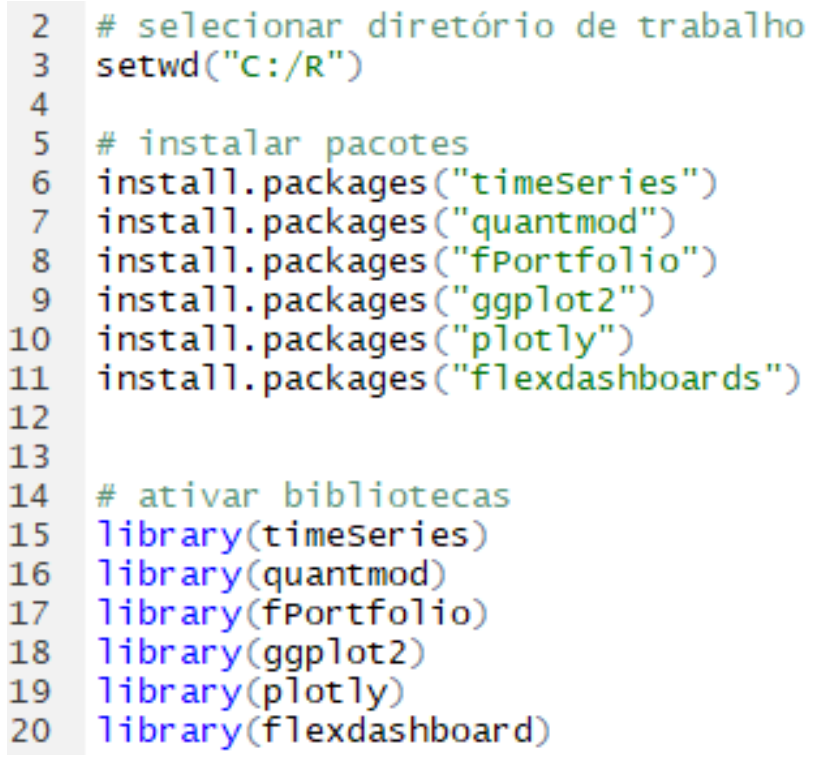

Após a disponibilização das bibliotecas já é possível a coleta e o pré-processamento dos dados das ações de interesse do investidor. Na fase de pré-processamento, convém estar atento a possíveis valores que não estejam disponíveis (?N/A? para tratamento, pois podem impactar no cálculo dos retornos e da fronteira eficiente.

Utilizando as funções disponíveis nas bibliotecas, podem-se calcular os retornos com base no preço de fechamento das respectivas ações. O algoritmo mostrado na Figura 2 realiza a etapa proposta:

Figura 2- Código dos cálculos de retorno

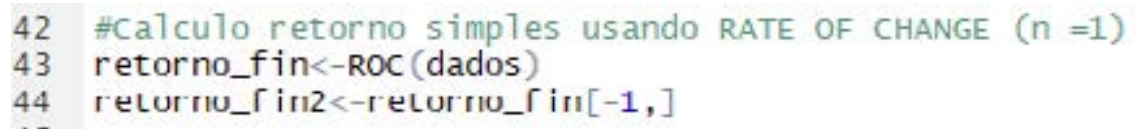


O cálculo da fronteira eficiente, segundo a Teoria de Markowitz, pode ser executado através de duas funções: a primeira da biblioteca timeSeries que será responsável pela conversão da base de dados em uma série temporal e a segunda da biblioteca fPortfolio que calculará a fronteira eficiente. As linhas de código exibidas na Figura 3 ativam as funções das respectivas bibliotecas e realizam o cálculo:

Figura 3- Código para cálculo da Fronteira Eficiente de Markowitz

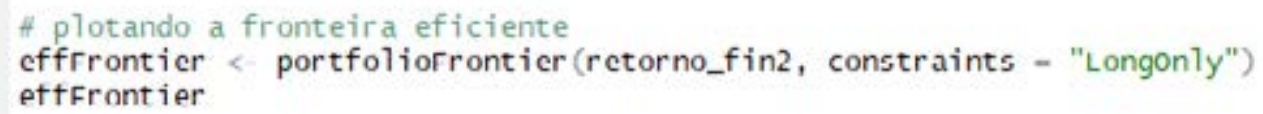

Para o cálculo da carteira com mínima variância, também será utilizada a função da biblioteca fportfolio. Segue na Figura 4 a função e os seus respectivos resultados:

Figura 4- Código para cálculo do portfólio de menor variância

53

54 FGet Minimum Variance Port, Tangency Port, etc.

ss mvp < minvarianceportfolio(retorno_fin2, spec-portfoliospec(), constraints-"Longonly"')

56 mvp

Analogamente ao cálculo da carteira de mínima variância, o cálculo da carteira como retorno máximo também é resultado da aplicação de uma função da biblioteca fPortfolio. $O$ código na Figura 5 realiza este cálculo e exibe os seus resultados:

Figura 5- Código para cálculo do portfólio de máximo retorno

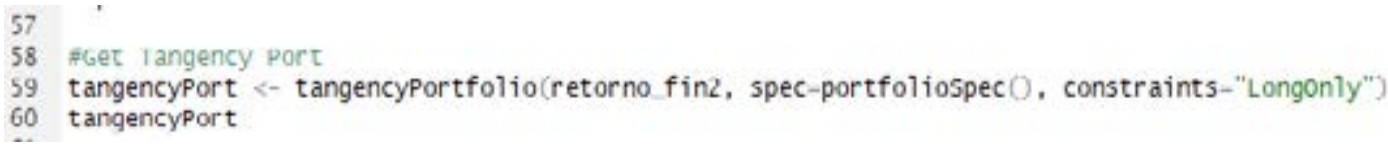

\subsubsection{Apresentação dos resultados}

Os Gráficos 3, 4 e 5 mostram os resultados encontrados para a Fronteira Eficiente de Markowitz e a distribuição de pesos tanto no portfólio de menor variância como também no portfólio de máximo retorno. 
Gráfico 3 - Fronteira Eficiente de Markowitz

\section{Efficient Frontier}

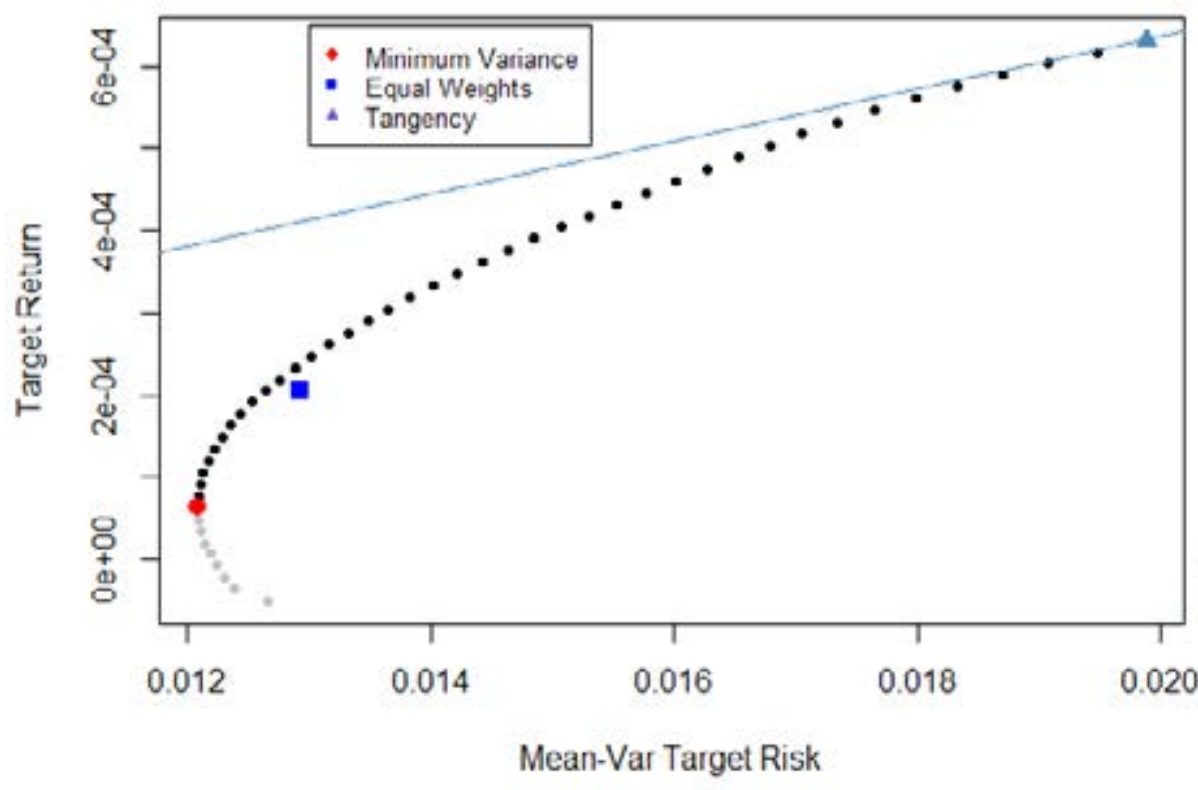

Gráfico 4 ? Distribuição de pesos das ações no portfólio de menor variância

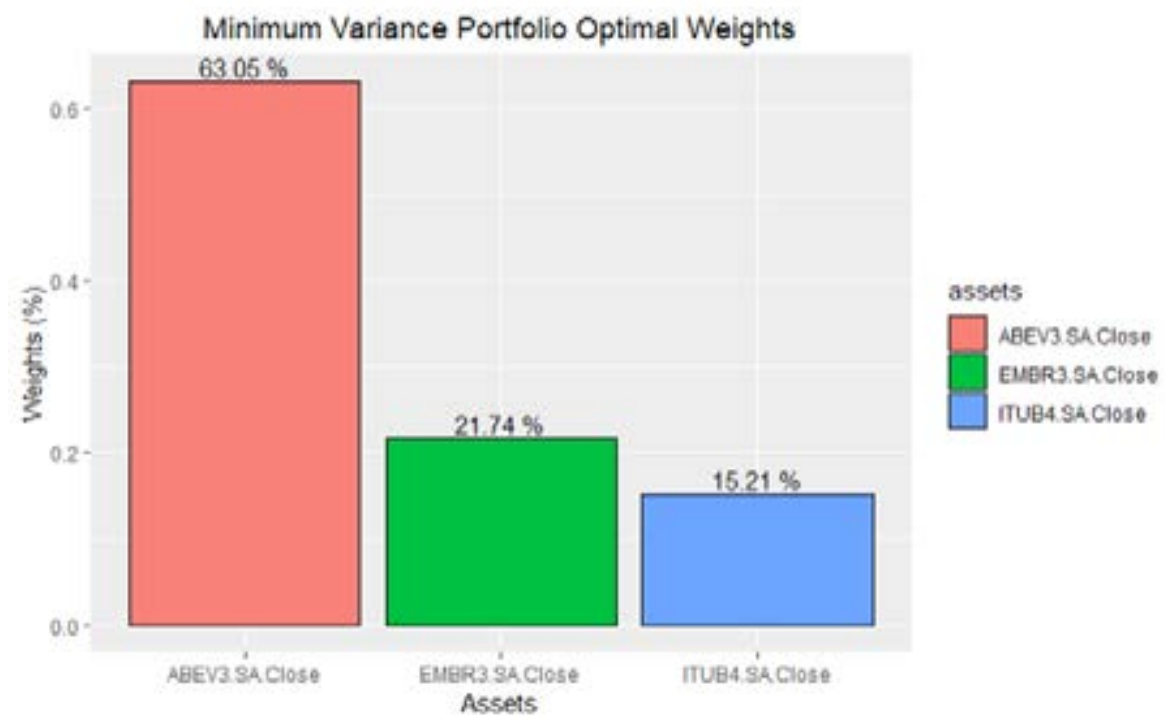


Gráfico 5? Distribuição de pesos das ações no portfólio de máximo retorno

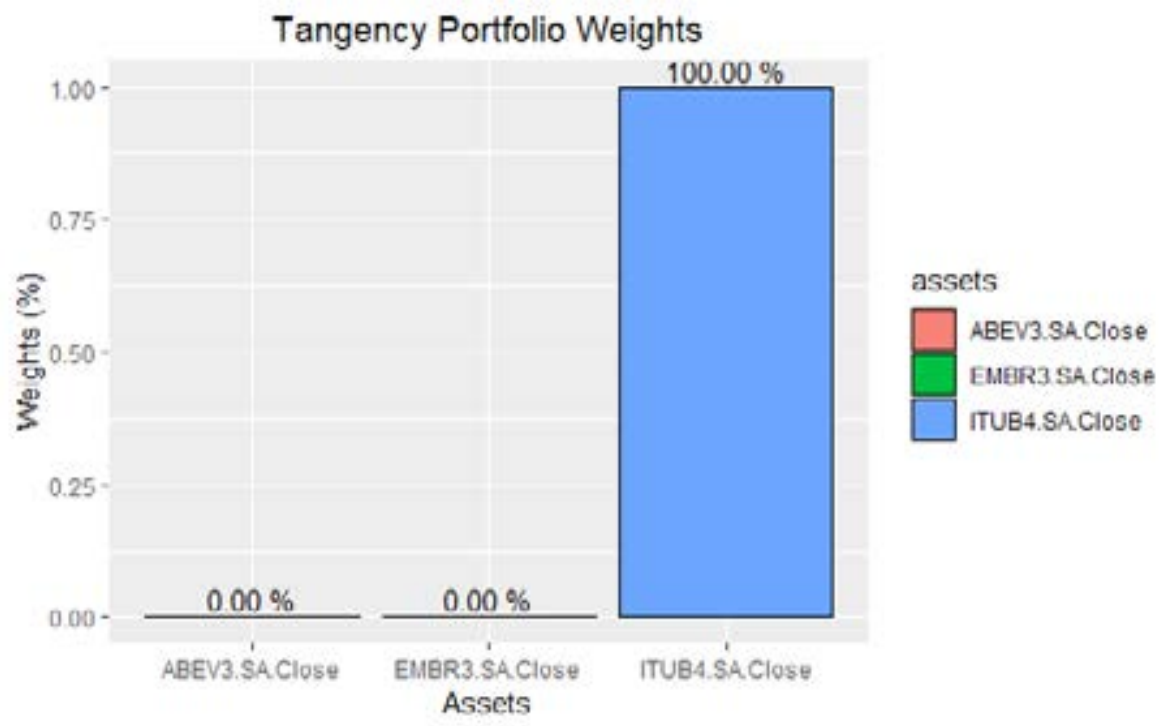

Após a execução dos códigos o modelo computacional apresentou os pesos tanto para o portfólio de mínima variância quanto para o de retorno máximo considerando os ativos propostos neste artigo considerando como exemplo as ações da Ambev, Embraer e Itaú.

Segundo Damodaran (1997, p.2), apesar dos modelos que são utilizados na avaliação poderem ser quantitativos, os dados de entrada sempre deixam margem suficiente para julgamentos subjetivos.

Diante disso, o processo de avaliação dos resultados proposto por este modelo não pode ser considerado de forma isolada, pois o mercado é dinâmico e exige do investidor, não só conhecimento do mercado e da empresa que faz parte do seu portfólio, mas principalmente grande capacidade de interpretação de diversas outras informações atreladas ao mercado onde se propôs a atuar como investidor.

\section{CONSIDERAÇÕES FINAIS}

A modelagem computacional se mostra extremamente útil para dar velocidade e reduzir a complexidade na resolução de problemas de finanças quantitativas envolvendo 
extração de dados, modelagem matemática, cálculo e criação de gráficos. Isto é exatamente o que torna esta abordagem aplicável na análise e seleção de ações de uma carteira de investimentos.

O aumento no volume da produção de informações, assim como das demandas sofridas pela humanidade nos últimos anos exige, cada vez mais, a automação de processos. Contudo, a intervenção humana se faz presente tanto na construção da modelagem computacional quanto na questão analítica.

Na questão proposta neste artigo pode-se observar que a tomada de decisão não fica restrita somente aos resultados obtidos pelo modelo. Apesar de o modelo ser capaz de fornecer informações importantes para a análise, outros fatores como: o cenário econômico local e mundial, as questões políticas envolvendo o mercado das ações em questão e o perfil do investidor interferem sobre a decisão final na seleção e composição de ações de uma carteira de investimento.

Este trabalho evidencia as possibilidades de utilização da modelagem computacional aplicando a Teoria de Markowitz como ferramenta de apoio na análise e seleção de ações para composição de uma carteira, porém sem negligenciar as principais questões que impactam a escolha de ações em um cenário de incerteza como é o mercado financeiro.

A API baseada neste trabalho encontra-se disponível no endereço eletrônico https://falcaoteste.shinyapps.io/apief/.

\section{REFERÊNCIAS}

ASSAF NETO, A. “Mercado Financeiro". Editora Atlas. 10 ed. - São Paulo: Atlas, 2011.

DAMODARAN, Aswath. "Avaliação de Investimentos: ferramentas e técnicas para a determinação do valor de qualquer ativo". Tradução de Bazán Tecnologia e Linguística (Carlos Henrique Trieschmann e Ronaldo Almeida Rego). Rio de Janeiro: Qualimark, 1997.

OLIVEIRA, M. D. B. "Introdução ao mercado de ações". CNBV - COMISSÃO NACIONAL DE BOLSAS DE VALORES, 1983. 
PINHEIRO, J. L. “Mercado de Capitais: fundamentos e técnicas”. São Paulo: Atlas, 2001.

ROSS, S.A.; WESTERFIELD, R.W.; JAFFE, J.F. Administração financeira. $2^{\circ}$. edição. São Paulo: Atlas, 2007.

REILLY F.K.; BROWN K.C. "Investment Analysis and Portfolio Management". The Dryden Press. Fifth Edition, 1997.

KAZMIER, LEONARD J. Estatística Aplicada à Economia e Administração/ Leonard J. Kazmier; tradução Carlos Augusto Crusius; revisão técnica Jandyara M. Fachel. - São Paulo: Pearson Makron Books, 2004.

\section{REFERÊNCIAS ELETRÔNICAS}

www.bmfbovespa.com.br. Acesso em: 21/10/2018, 23/10/2018, 09/11/2018 e 10/11/2018. https://www.rstudio.com/. Acesso em: 01/10/2018.

https://finance.yahoo.com/. Acesso em: 10/10/2018 e 10/11/2018.

https://cran.r-project.org/. Acesso em: 05/11/2018 e 07/11/2018. 